\title{
Motivational Orientation as an Internal Marketing Tool in Service Training: A Study of Service Delivery in a Hospital
}

\author{
Rahim Mosahab, PhD Candidate (Corresponding author) \\ School of Management, Universiti Sains Malaysia (USM), Malaysia \\ E-mail: rmosahab@yahoo.com \\ Osman Mahamad (Professor) \\ Graduate School of Business, Universiti Sains Malaysia (USM), Malaysia \\ E-mail: osman@usm.my \\ T. Ramayah (Associate Professor) \\ School of Management, Universiti Sains Malaysia (USM), Malaysia \\ E-mail: ramayah@usm.my
}

\begin{abstract}
This research analyzes the various socio-psychological orientations of hospital service employees towards service training in the Imam Khomeini hospital, Tehran, Iran. The study focuses on instrumental and integrative orientations of employees in taking service training. In order to determine the employees' tendency towards the mentioned orientations, a sample of 255 employees was given a questionnaire based on Gardner's Attitude/Motivation Test Battery (AMTB). Findings of the present study shows that the hospital employees are both instrumentally and interactively oriented towards service training. This study of socio-psychological variables of the employees provides additional insights in better identifying motivational challenges and taking more realistic perspectives about the service training as an instrument of internal marketing (IM). Finally, suggestions for managers and some recommendations regarding future researches in this area have been highlighted.
\end{abstract}

Keywords: Internal Marketing (IM), Motivational orientation, Service training, Hospital

\section{Introduction}

Internal Marketing (IM) was proposed by Berry in 1976 to solve the problem of service quality using external customers' strategies on employees so called internal customers. The job is considered as product which should be designed in such a way that will meet human needs and motivate them to offer high quality service (Berry, 1976). Since then there have been numerous conceptual and empirical researches on the issue (e.g. Berry \& Parasuraman, 1991;Tsai \& Ta-Wei, 2008; Anosike \& Ahmed, 2009; Grant, 2010; Owusu-Frimponga \& Martinsb, 2010). For example, Berry \& Parasuraman (1991), states:

"Internal marketing is attracting, developing, motivating and retaining qualified employees through job-products that satisfy their needs. Internal marketing is the philosophy of treating employees as customers and it is the strategy of shaping job products to fit human needs".

Service training has been known as one of the most important instruments of IM to satisfy the service employees from their jobs and motivate them to offer higher quality services. Training plays a role in gaining these skills. It is, therefore, reasonable to expect that service providers who acquire more training opportunities are more likely to show higher levels of job satisfaction and organizational commitment (Lee et al., 1999).

In order to enhance service quality, training is an important task that cannot be neglected. As a result of that, some researchers feel that the need for service training in the service firm has become larger and one of the main concerns. Service training is the important factor affecting employee turnover. According to Callan (1994), service training programs should be developed by the managers to meet the specific needs of targeted markets. However, according to Breite \& Woods (1997), many service operations have yet to implement structured service training programs. 
According to Forrest (1990), training cannot be the solution to every operational or performance problem, nor the cure-all for all human resource related problems. Service training is used to help managers communicate the requisite knowledge, skills and attitudes for employees to help them perform satisfactorily in their current and future roles (Pepitone, 1995).

Motivation has been widely accepted by both managers and researchers as one of the key factors that influence the rate and success of employee performance. Gardner (1985) argues that, motivational orientation has direct effect towards a set of goals, either with a strong interpersonal quality (integrative) or a strong practical quality (instrumental).

The present study intended to highlight the extent of service employees' motivation in having service training and their differences in instrumental and integrative orientations. Furthermore, the findings of the study may promise some improvements and changes regarding the implementation of service training.

\section{Literature review}

The service literature highlights the importance of employees, particularly the motivation of those employees, in successful service firms (Lovelock, 1994). Some experts emphasize the importance of 'commitment' (Farber \& Wycoff, 1991), others emphasize the importance of 'culture' (Collier, 1994), and still others emphasize 'climate' (Schneider, 1980). They are all in agreement with Hostage (1975), who states, "Service quality begins with people".

The courtesy, empathy, and responsiveness of service employees all combine to influence quality perceptions of customers (Parasuraman et al., 1988). Czepiel et al. (1985) argue that, "employees not only deliver and create the service, but are actually part of the service in the customers' view". Motivated employees, who have a clear vision of the importance of service quality to the firm, should provide superior service (Bowen \& Lawler, 1992). Employee motivation is thought to be an essential ingredient of learning organizations (Marquardt \& Reynolds, 1994).

Most experts agree that, in a learning organization whose employees are motivated to be trained and understand the importance of service quality to the organization, will be willing to learn and will achieve superior service quality. As Albrecht \& Zemke (1985) assert, employee motivation and organizational learning are thought to positively affect perceived service quality.

Previous researches have focused on two types of motivation: motivation to learn or train and motivation to transfer (compare Clark, Dobbins, \& Ladd, 1993; Noe, 1986; Noe \& Schmidt, 1986; Hicks \& Klimoski, 1987; Mathieu and Martineau, 1997; Mathieu, Tannenbaum, \& Salas, 1992; Seyler, Holton, Bates, Burnett, \& Carvalho, 1998; Warr \& Bunce, 1995). In both types, the desired outcome of organizational training programs is to improve work outcomes. This research investigates the employee's willingness as a function of motivation to learn for different outcomes.

The category training group articles discuss the planned educational programs and activities that organizations use to improve employee performance, behavior, and satisfaction. This section includes the work of Ottenbacher \& Gnoth (2005); Jarvi (2000); Czaplewski, et al (2001); Haywood (1992); Harrington \& Williams (2004); Wildes (2002); Babakus, et al (2003); McCleary \& Weaver (1988); Liljander (2000); and Voss, Keller, Ellinger, \& Ozment (2004).

Ottenbacher \& Gnoth (2005) highlight worker training as an employee-management aspect important to organizational success. Jarvi (2000) identified the management of human resources and employee training as basic internal marketing activities, while Czaplewski, et al (2001) cite equipping staff with the skills and information needed to perform as a key strategy in implementing internal marketing. While he believes the main purpose of training is to enable organizations to compete more effectively, Haywood (1992) also feels a central goal is to link training effectiveness with employee performance.

Harrington \& Williams (2004) consider human resources major company assets and believe workers' knowledge and skills can be effectively enhanced through training and participating in organizational mission, vision, and strategy development. Wildes (2002) largely attributes the success of the food and beverage venue featured in her case study to the use of experimental, learned, and specifically targeted training methods, which emphasize on teamwork, employee satisfaction, and over the top service (p. 195).

Babakus et al. (2003) specify training as the third most important construct (after empowerment and rewards) customer-contact employees use to determine management's commitment to service quality; and, they state that training and development initiatives are needed for empowered employees to succeed. McCleary and Weaver (1988) think it is important for management to develop an understanding of the different expectations held by 
various human resource segments. They found, for example, that women place more significance on training than men.

Liljander (2000) explains how having employees whose individual needs are met can translate into increased worker commitment, lower turnover, and reductions in education (training) costs. And Voss et al. (2004) claim that creativity in supervisor and coworker training may generate a greater awareness of elements of the internal marketing mix...most applicable for creating satisfaction among workers (p. 49). Brown (2001) states that, motivation refers to the intensity of one's impetus to learn. The intensity or motivation of a learner to attain that goal could be high or low (p.75).

The present research framework has driven much of the research on motivation by Gardner's (1985, 1988; Gardner and Macintyre 1993). Gardner and his colleagues found that integrative motivation was more powerful than instrumental integration, which refers to the practical value and advantages.

\subsection{Research hypothesis}

Regarding the corresponding and directional literature, the following hypotheses were formulated for this study:

H1: Employees are highly motivated towards service training.

$\mathrm{H} 2$ : There is a significant difference among the integrative orientations of the employees among employees of each profession and also among employees of all three professions.

H3: There is a significant difference among the instrumental orientations of the hospital service employees among employees of each profession and also of all three professions.

H4: There is a significant difference between the instrumental and integrative orientations of the all three service profession.

H5: There is a significant difference between the instrumental and integrative orientations among employees of each profession.

\section{Methodology}

\subsection{Participants}

In this study a number of 300 employees (male and female) were selected by random sampling from the total population of 980 in nursing, medical technology and food service professions in Imam Khomeini. A total of 255 completed questionnaires were returned.

\subsection{Procedure and Instrumentation}

The Integrative and Instrumental Orientation scales of the original 7-point Likert Scale format of Gardner's Attitude/Motivation Test Battery (AMTB) (Gardner, 1985) were adapted to a 5-point scale, ranging from 'Strongly Agree' to 'Strongly Disagree'. The AMTB is reported to have good reliability and validity (Gardner, 1985; 1980; Gardner and Smythe, 1981) and the internal consistency estimate of reliability for the modified questionnaire was calculated, and Cronbach's Alpha was 0.7. The purpose and different terms of the questionnaire were explained before the distribution. During the completion process of the questionnaire, the researchers were present physically to monitor and also to help the respondents to understand certain parts. Respondents were given 5 minutes to complete the questionnaire and were informed that the information they gave would be kept confidential and be used for research purposes only.

\subsection{Design}

In this study, the major focus was on various socio-psychological variables rather job proficiency levels which were not tested. The questionnaire as mentioned above was adopted from Gardner's AMTB (1985).

Followings are the variables that were assessed using Likert scale (modified 7 point to 5 scale point) ranging from agreement to disagreement:

3.3.1 Integrative Orientation: The scale includes four items to find out how much the employees learn service training material with a genuine interest.

3.3.2 Instrumental Orientation: On this scale, there are four items and the respondents are asked to measure their utilitarian reason.

\section{Results and discussions}

The raw data was fed into the computer and then was analyzed by using SPSS. The results are discussed below: 
The respondents were asked to indicate on a five point scale how important each reason was for their learning service training material. The focus was on two types of motivational orientation: Integrative and Instrumental.

Descriptive statistics were carried out for all measures involved in this study. Comparison between the mean scores of the three professions illustrated that employees were highly motivated in Q1, Q2, Q5, Q6 and Q7. Questions three, four and eight (Q3, Q4, Q8) showed the employees' performance motivation and no lack of motivation was observed among the eight questions.

As shown in tables 1, 2 and 3 most of the employees are highly motivated in taking service training. In comparison to other questions, question number eight which asked if people had a more respect, showed the lowest level of motivation. It can be concluded that cultural factors might have prevented them from showing a higher motivation for this question. Variables such to be at ease, need for career and need for promotion are significant in acquiring service training.

But still this question along with the questions number 3 and 4 show a desirable amount of motivation. No question is reported to show lack of motivation. The results show moderate to high motivation toward service training. Therefore, the first hypothesis is approved. In order to find the answer to the second question and investigate the second research hypothesis, statistical method of one way analysis of variance (one way ANOVA) was concluded.

As table 5 illustrates, there are no significant differences in integrative orientation of each profession and also among the employees of all three profession. This result rejects the second hypothesis and confirms that employees are closely related in their integrative orientation.

Table 6 illustrates the differences in instrumental orientations of each profession and employees of the three professions. No significant difference is observed in their level of instrumental motivation. Therefore, the third hypothesis is rejected as well.

Table 7 shows the differences between the instrumental and integrative orientations of employees. In order to determine this difference among the employees T-test for independent groups has been selected and the results do not show any meaningful differences in this regard. As a result, the fourth hypothesis is not confirmed.

In the last table (table 8) a T- test was used to determine the difference between integrative and instrumental orientations of each profession. As the following results show there was no significant difference between these two orientations and employees are both instrumentally and interactively motivated. This means that the last hypothesis is also rejected.

\section{Conclusion}

This study was conducted to probe the motivational orientations of hospital service employees. The findings present a picture which establishes that the hospital employees are both instrumentally and interactively oriented towards service training. This provides a sufficient answer to the research questions addressed. Also it was shown that employees are highly motivated towards taking service training. In general, findings of this research are in line with the previous findings brought in the literature review section

An implication of the findings is that motivational orientation of employees, as a significant factor, should be considered in service training planning and implementation. Many managers believe that by sticking to the training materials and trying to discipline their refractory employees, they will manage to create a classroom environment that will be conductive to learning. Nevertheless, these managers seem to lose sight of the fact that, unless they accept their employees' personalities and work on those minute details that constitute their social and psychological make-up, they will fail to motivate them therefore managers can improve their methods of service training by considering the domain of motivation. Furthermore, other related researches regarding the relationship between these two orientations and employees achievements are considered to be useful.

The study did not aim to find out the link between varieties of motivational orientations and the job proficiency of the employees. Future studies could aim at these issues and could give more insights to the service training. The results of the present study though show hospital employees are both instrumentally and interactively motivated, but the limitation of participants to three professions of one hospital do not allow one to conclude that in general all employees of Iran are purely instrumentally and interactively motivated. More research in this area needs to be conducted.

\section{Acknowledgement}

The present research was supported by a fellowship allowance offered by the School of Management and Institute of Postgraduate Studies (IPS) at Universiti Sains Malaysia (USM). 


\section{References}

Albrecht, K., \& Zemke, R.E. (1985). Service America. Irwin (Richard D.), Homewood, IL.

Anosike, U.P., \& Ahmed, P.K. (2009). Internal marketing: focus on practice. International Journal of Management Practice, 3(4), 369 - 382.

Babakus, E., Yavas, U., Karatepe, O. M., \& Avci, T. (2003). The effect of management commitment to service quality on employees: affective and performance outcomes. Academy of Marketing Science Journal, 31(3), 272-286.

Berry, L. (1976). Improving retailer capability for effective consumerism response. Journal of Retailing, 52(3), 3-14, 94.

Berry, L. L., \& Parasuraman, A. (1991). Op. cit, 151.

Bowen, D. E., \& Lawler III, E.E. (1992). The empowerment of service workers: what, why, how, and when. Sloan Management Review, 33(3), 31-39.

Breite, D., \& Woods, R. H. (1997). An analysis of training budgets and training needs assessments in mid-sized hotels in the United States. Journal of Hospitality \& Tourism.

Brown, H. D. (2001). Teaching by principles: an interactive approach to Language pedagogy. Addison Wesley Longman, Inc. (2ed.).

Callan, R. J. (1994). Quality assurance certification for hospitality marketing, sales and customer services. The Services Industries Journal, 14(4), 482-499.

Clark, C. S., Dobbins, G. H., \& Ladd, R. (1993). Exploratory field study of training motivation: Influence of involvement, credibility, and transfer climate. Group and Organization Management, 18, 292-307.

Collier, D. A. (1994). The Service/Quality Solution Using Service Management to Gain Competitive Advantage. Irwin (Richard D.), Milwaukee, WI.

Czaplewski, A. J., Ferguson, J. M., \& Milliman, J. F. (2001). Southwest airlines: How internal marketing pilots success. Marketing Management, 10(3), 14-17.

Czepiel, J. A., Solomon, M.R., \& Surprenant, C.F. (1985). The Service Encounter, Managing Employee/Customer Interaction in Service Businesses. Lexington Books, Lexington, MA.

Farber, B., \& Wycoff, J. (1991). Customer service: evolution and revolution. Sales and Marketing Management, 44-51.

Forrest, L. C. (1990). Training for the hospitality industry. The Educational Institute of the American Hotel \& Motel Association, East Lansing, MI.

Gardner, R. C. (1980). On the validity of affective variables in second language acquisition: conceptual, contextual and statistical considerations. Language Learning, 30, 255-270.

Gardner, R. C. (1988). The socio-educational model of second language learning: Assumptions, findings, and issues. Language Learning, 38, 101-126.

Gardner, R. C., \& Macintyre, P.D. (1993). A student's contributions to second language learning: Affective variables. Language Teaching, 26(1), 1-11.

Gardner, R. C., \& Smythe, P.C. (1981). On the development of the attitude/motivation test battery. Canadian Modern Language Review, 37, 510-525.

Gardner, R. C., Lalonde, R.N., \& Moorcroft, R. (1985). the role of attitudes and motivation in Second Language Learning: Correlational and Experimental Considerations. Journal of Applied Linguistics, 35(2), 207-227.

Grant, B. David. (2010). Integration of supply and marketing for a blood service. Management Research Review, $33(2), 123-133$

Harrington, D., \& Williams, B. (2004). Moving the quality effort forward - the emerging role of the middle manager. Managing Service Quality, 14(4), 297-306.

Haywood, K. M. (1992). Effective training: Toward a strategic approach. Cornell Hotel and Restaurant Administration Quarterly, 33(6), 43-52.

Hicks, W. D., \& Klimoski, F. J. (1987). Entry into training programs and its effects on training outcomes: A field experiment. Academy of Management Journal, 30, 542-552. 
Hostage, G. M. (1975). Quality control in a service business. Harvard Business Review, 53(4), 98-106.

Jarvi, P. (2000). The internal marketing and the commitment of the employees when managing the customer-oriented business. [Online] Available: http://www.sba.muohio.edu/abas/2000/PRAHA2002.pdf

Lambert, W. E. (1974). Culture and language as factors in learning and education. In F. F. Aboud \& R. D. Meade (Eds.). Cultural factors in learning and education, Bellingham: Western Washington State University, $91-122$.

Liljander, V. (2000). The importance of internal relationship marketing for external relationship success. Relationship marketing: Gaining competitive advantage through customer satisfaction and customer retention, Springer Verlag: Berlin, 159-192.

Lovelock, C. H. (1994). Product Plus. McGraw-Hill, New York.

Marquardt, M. J., \& Reynolds, A. (1994). The Global Learning Organization. Irwin (Richard D.), New York.

Mathieu, J. E., \& Martineau, J. W. (1997). Individual and situational influences on training motivation. Improving training effectiveness in work organizations, In J. K. Ford, S.W.J. Kozlowski, K. Kraiger, E. Salas, \& M. S. Teachout (Eds.)(Hillsdale, NJ: Erlbaum), 193-221.

Mathieu, J. E., Tannenbaum, S. I., \& Salas, E. (1992). Influences of individual and situational characteristics on training effectiveness measures. Academy of Management Journal, 35, 828-847.

McCleary, K. W., \& Weaver, P. A. (1988). The job offer: what today's graduates want. Cornell Hotel and Restaurant. Administration Quarterly, 28(4), 28-31.

Noe, R. A. (1986). Trainee attributes and attitudes: Neglected influences on training effectiveness. Academy of Management Review, 11, 736-749.

Noe, R. A., \& Schmidt, N. (1986). The influence of trainee attitudes on training effectiveness: Test of a model. Personnel Psychology, 39, 497-523.

Ottenbacher, M., \& Gnoth, J. (2005). How to develop successful hospitality innovation. Cornell Hotel and Restaurant Administration Quarterly, 46(2), 205-222.

Owusu-Frimponga, N., \& Martinsb, A. (2010). Adoption and Implementation of Internal Marketing Systems by Ghanaian Small- and Medium-Sized Enter. Journal of African Business, 11(1), 26 - 48.

Parasuraman, A., Zeithaml, V.A., \& Berry, L.L. (1988). SERVQUAL: a multiple-item scale for measuring consumer perceptions of service quality. Journal of Retailing, 64(1), 12-40.

Pepitone, J. (1995). Future training: A roadmap for restructuring the training function. Dallas, TX: AddVantage Learning Press.

Schneider, B. (1980). The Service Organization: Climate is Critical. Amacom, New York.

Seyler, D. L., Holton, E. F. III, Bates, R. A., Burnett, M. F., \& Carvalho, M. A. (1998). Factors affecting motivation to use training. International Journal of Training and Development, 2, 2-16.

Tsai, Y., \& Ta-Wei, T. (2008). How to improve service quality: Internal marketing as a determining factor. Total Quality Management \& Business Excellence, 19(11), 117- 126.

Voss, M. D., Keller, S. B., Ellinger, A. E., \& Ozment, J. (2004). Differentiating the suppliers of job products to union and non-union frontline distribution center employees. Transportation Journal, $37-58$.

Warr, P., \& Bunce, D. (1995). Trainee characteristics and the outcomes of open learning. Personnel Psychology, 48, 347-375.

Wildes, V. J. (2002). Unique training: The mood indicator is an employee's tool. International Journal of Contemporary Hospitality Management, 14(4), 193-196.

Table 1. Frequency and percentage of participants

\begin{tabular}{|c|c|c|}
\hline Profession & Frequency (f) & Percentage \\
\hline Nurse & 177 & 69.4 \\
\hline Med Technologist & 53 & 20.8 \\
\hline Food service & 25 & 9.8 \\
\hline Total & 255 & 100 \\
\hline
\end{tabular}


Tables 2\&3. Mean score of integrative motivation \& Mean score of instrumental motivation

\begin{tabular}{|l|c|}
\hline \multicolumn{1}{|c|}{ Questions } & Mean score \\
\hline Q1: to be at ease with the job & 4.16 \\
\hline Q2: to meet the high quality service & 3.90 \\
\hline Q3: to understand and appreciate job & 3.43 \\
\hline Q4: to act more freely in activities & 3.47 \\
\hline Q5: to fulfill need it for the career & 4.07 \\
\hline Q6: make more knowledgeable & 3.98 \\
\hline Q7: to be useful in the job promotion & 4.19 \\
\hline Q8: to receive people's respect & 2.67 \\
\hline
\end{tabular}

Table 4. Desirable level of motivation among the employees

\begin{tabular}{|c|c|c|}
\hline Less desirable & Desirable & Highly desirable \\
\hline 1 to 2.3 & 2.3 to 3.7 & 3.7 to 5 \\
\hline
\end{tabular}

Table 5. F value for differences among integrative orientation of employees

\begin{tabular}{|l|c|c|c|c|c|}
\hline Source of changes & Sum of squares & Df & Mean squares & F & Sig. of F \\
\hline Between groups & 20.695 & 2 & 10.347 & 2.028 & 0.134 \\
\hline Within groups & 1285.643 & 252 & 5.102 & & \\
\hline Grand mean & 1306.337 & 254 & & & \\
\hline
\end{tabular}

Table 6. F value for differences among instrumental orientation of employees

\begin{tabular}{|l|c|c|c|c|c|}
\hline Source of changes & Sum of squares & Df & Mean squares & F & Sig. of F \\
\hline Between groups & 13.444 & 2 & 6.722 & 0.88 & 0.41 \\
\hline Within groups & 1919.82 & 252 & 7.618 & & \\
\hline Grand mean & 1933.271 & 254 & & & \\
\hline
\end{tabular}

Table 7. T test for differences between integrative and instrumental orientations of employees

\begin{tabular}{|l|l|c|c|c|c|c|c|}
\hline Variable & Orientation & Mean & Std. & T test & Df & Sig. of T & N \\
\hline Motivational & Integrative & 14.94 & 2.26 & & & & 255 \\
\cline { 2 - 6 } \begin{tabular}{l} 
Orientation \\
\cline { 2 - 8 }
\end{tabular} & Instrumental & 14.91 & 2.75 & 0.14 & 508 & 0.88 & 255 \\
\hline
\end{tabular}

Table 8. Differences between instrumental and integrative motivation of employees of each profession

\begin{tabular}{|l|l|l|l|l|l|l|l|}
\hline Profession & Orientation & Mean & Std. & T & Df & Sig. of T & N \\
\hline Nurse & Integrative & 15.1 & 2.21 & 0.48 & 352 & 0.62 & 177 \\
& Instrumental & 14.97 & 2.77 & & & & \\
\hline Food service & Integrative & 14.16 & 2.39 & \multirow{2}{*}{1.95} & 48 & 0.056 & 25 \\
& Instrumental & 14.16 & 2.39 & & & & \\
\hline Technologist & Integrative & 14.81 & 2.34 & 0.53 & 104 & 0.59 & 53 \\
& Instrumental & 14.52 & 3.04 & & & & \\
\hline
\end{tabular}




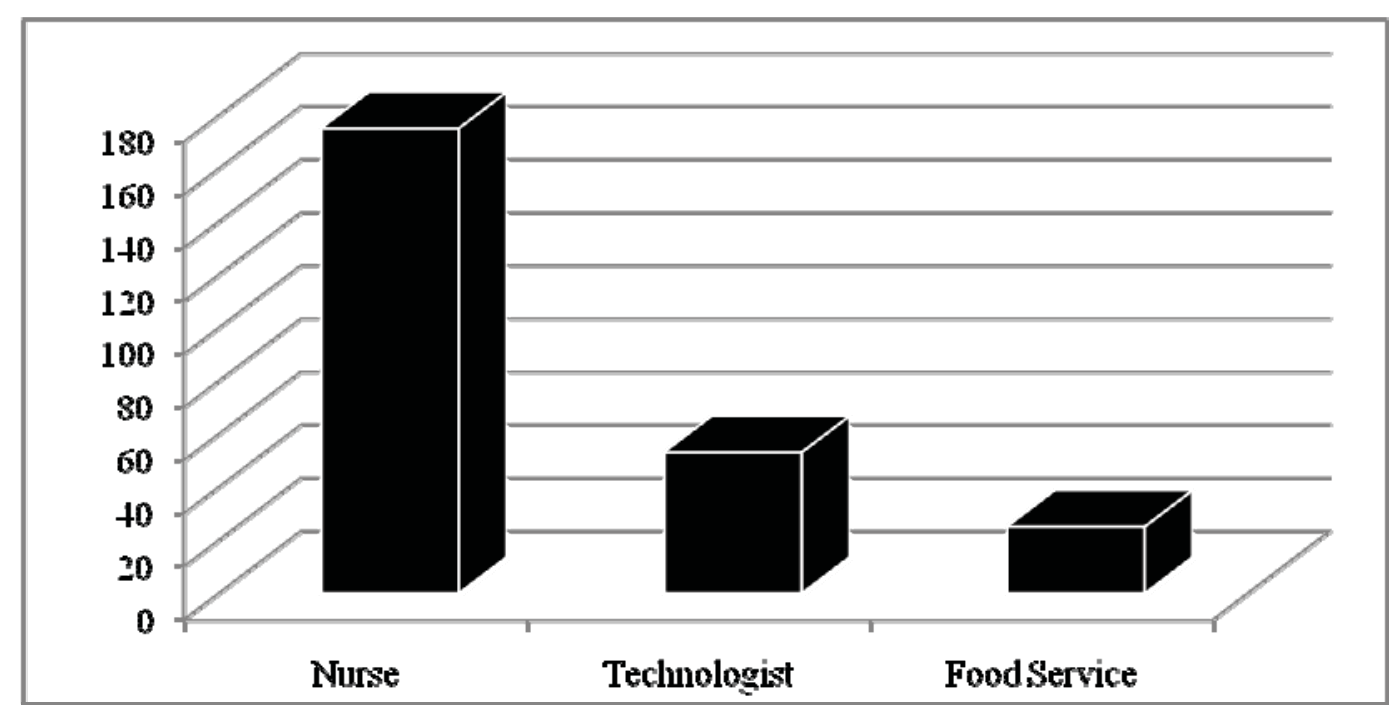

Chart 1. Participants Frequency 